\title{
Critical Discourse Analysis (CDA) on Qualitative Research: A Review
}

\author{
Rika Armayanti \\ Department of English Education, Universitas Lancang Kuning, Indonesia \\ ikaarmayantiika@gmail.com
}

\section{ARTICLE HISTORY}

Received : 2019-06-08

Revised : 2019-06-16

Accepted :2019-06-20

\section{KEYWORDS}

Critical discourse analysis

Qualitative research

Analysis of text

Human text

\begin{abstract}
This article discusses critical discourse theory as a qualitative research theory. Analytical frameworks include analysis of texts, communication and social practices in local, corporate and social levels. It has the goal of expressing and engaging in politics to discuss or deal with specific research methods, statements or values. It refers to the need to explain, understand, analyze, and criticize social life that reflects in the text using critical discourse analysis. According to Lake (1996), "The authors use texts to understand their world, and at the same time, the article admits to creating actions and social relationships in everyday life, while text positions and individual buildings provide different meanings, ideas, and world versions".
\end{abstract}

\section{Introduction}

According to Anyon (2009), "Theory and academic research divides old-age theory by demonstrating how researchers use critical theory to assess appropriate experimental research techniques and demonstrate analytic, critical and sometimes liberal data storage and definition".

Dressman (2008) said that is the theory encompasses thinking methods about academic issues and inhibits creativity among researchers, policymakers, and teachers. According to Anyon (2009), "There are five types of arguments used in the theory of academic research. 1). Analogous arguments (however, argue that the success of natural sciences in the use of theory is an excellent example of academic research, but that theory should be relatively useful when we move from one subject to another); 2). Reconciliation of Experience (The most important way to think about the role of theory is to directly override the problem of identifying the need for theory); 3). Identification of Complexity (appearing on the surface, as in the simplest case of experimental investigation, to prove complex in a deeper sense). 4). Deweyan Problem solvent (trial is an unspecified transformation that is subject to a problem determined and integrated by early problem solving); and 5). Bear Experiment Minorities (There are no devices for recording and generalization of theory or theory).

According to Maxwell (2010), "Lies, analysis, or interpretation theory is free." Be aware that the problem is about the theory of one being used and whether it is critical or suspicious. To understand any academic phenomenon, the phenomenon needs to look at the larger socio-economic and political scenarios that are embedded and to find theories that connect there. Not only does it understand the study of individuals, situations, and studies, but also theories can be used to change them. To avoid citing the theory to support one's argument, it must be used to adapt the theory to one's study logic and to deepen one's research process.

Formal learning and instructional techniques are inseparable. Learning theories further illustrate how learning occurs, but does not describe specific methods and activities to follow the objective learning results. For example, learning theories can explain the age that students can learn breaks, but instructional theories provide guidelines on how to implement break instruction.

\subsection{CDA: Primary Interest in Qualitative Research}

According to Van Dijk (2006), "CDA is main interested and motivated by the idea of comprehensions social issues." According to Hamuddin (2012) in Sahat (2018), the term "discourse" is a complex and mammoth-like interpretation. Many previous studies mention the term discourse as very ambiguous since its introduction to modern science and the various broad interpretations of discourse." Wodak and Meyer (2009) argue that critical discourse analysis emphasizes the need for interdisciplinary work to gain a sense of how to create knowledge in the organization of social organizations and how to spread knowledge. According to Rogers et al. (2005), "Critical theories are usually about the issues of power and justice, and to create, reproduce, or 
transform social systems such as the economy, race, class, gender, religion, education, and sexual orientation." Human subjects use texts to understand their world and create different meanings, concepts, and editions of the world, at the same time, at the same time as the workers' lives, and in the form of individuals (Lake: 1996).

The analysis includes analysis of texts, communication and social practices at local, organizational and social levels. CDA deals with the long-term analysis of the basic causes and the effects of problems. Therefore, it requires an account of detailed relationships between text, discussion, society, and culture. Teaching and learning policies can better understand the language and type of texts by looking at community social issues. According to McGregor (2010), CDA dares us to move our speech to an abstract view to see our words in past particular, public and political situation.

Therefore definitive discourse analysis is realized and expanded, and instances of social communication take a particular linguistic form (Blommaert \& Bulcaen: 2000). CDA is intended to systematically explore occasional opacity and determination between discord practices, events and texts, and broader social and cultural structures, relationships, and processes (Locke: 2004). Investigate how such practices, events, and texts arise and develop theories of power and theories of power formed as a theory. It is aimed at disclosing motivation and politics that are subject to a specific research method, statement, or value or argument".

The texts are moments of inter-subjectivity, that is, social and conflicting relationships between human subjects, such as writers and readers, speakers, and listeners, because their motives are self-evident or unrecognized individuals without help in another text (Lake:1996). CDA is a tool that helps members of the profession understand the messages they and others are sending and others understand and understand the meaning of written texts, words of the authorities are considered "self-evident truths" and the words of those who are not in power are dismissed without irrelevant, inadequate or material (McGregor:2010). This is an unacceptable understanding because educators should also be involved in the development of teaching and learning policies. The texts also have major social institutions such as schools and offices in the departments of education, critical discourse analysis that emphasizes the analysis of such basic documents.

CDA is primarily in the language environment, and its success can be measured by a radical measurement of languages. Language speakers can use the speaker's beliefs, positions, and ideas to represent the spoken texts, such as conversations. If we analyze the underlying meaning of the word, written or verbal messages will show meaning. Analysis of underlying meanings can help teachers explain the problems, situations, and events they find themselves. Using words can be controlled by the education system. Critical discourse can only contribute significantly and definitively to critical social or political analysis if it can provide the role of language, language use, discourse or expression in the production of dominance and inequality (Van Dijk: 2006; McGregor: 2010). The focus of the theory and practice of critical discourse analysis is on the formation and discussion of texts.

CDA determines the right text and the relationship between listening, speaking, reading and writing processes. Thus, it provides the ability to analyze the written text critically, what we write, and what we say. McGregor (2010) gives the written and spoken word power; critical discourse analysis is needed to explain, interpret, analyze and criticize the reflective social life. Educators are mandatory about the language of learning and teaching to implement teaching and learning policies.

According to Rogers et al (2005), "The analyst's first goal is to explain the relationship between certain texts, communications, and social practices; the second goal is to interpret the structure of discourse systems; and the third goal is to use explanation and definition to explain why and how social practices are formed, vary, and how they are transformed". The goals, options, and criteria for critical discourse analysis that control the theory of theory, analytic method and procedural research methods (Van Dijk: 2006). Lake (1996) argues that critical discourse analysis can make transparent asymmetries in relationships, which texts reveal text tricks to establish, detect, define, and in some cases, enable and control readers and addresses.

The discourse is socially structured and socially restricted; it includes situations, knowledge materials, and social markings and relationships between people and groups of people (Wodak: 2009). Lake (1996) says that the task or function of critical discourse is to say, breaking and criticizing texts as a way to disrupt common knowledge. Interactive discourse analysis can be viewed as a critique of critical texts. It is intended to help understand the social issues of intermediate theory and power relations, and remain in use of written texts in all our daily and professional lives. The context of language is crucial, which treats language as a social practice. Written and spoken texts must be critically and constructively analyzed. DA what we do when we judge texts or conversations and the value and truth of relevant documents.

DA helps us to raise awareness about the hidden motives of others and thus help us solve concrete problems, by providing unequivocal answers, but by asking philosophy and cognitive questions (Olson: 
2007). Thus, it does not give full answers to a specific problem but allows us to understand the conditions behind a particular problem and the essence of that problem and its determination to assume that its assumptions are false, and that is the problem. It can be applied to any text for any text or situation. Critical analysis tells us that it's going on behind our backs and deciding on others and our actions. Evaluation of a particular research method, statement, or value does not argue or argue against the truth but focuses on the existence and message of texts.

CDA dies-close a concept that is hidden in our written text or oral speech, and we do not use it (McGregor: 2010). It intends to systematically explore opaque relationships between adverse practices, texts and events and extensive social and cultural structures, relationships and processes.

According to McGregor (2010), "Deciding discourse analysis aims to combine and affect the relationship between three critical analyses:"

a) Guest text.

b) Automatic practices larger social context for text and explanatory practices.

\section{c) Power legislation and discourse production}

CDA seems to establish a connection between texts, discourse (text production, use, and distribution), and broader social-cultural practice (Fairclough: 1995). The purpose is "shadow" and analyzed transparent structural relationships, as analyzed in a language in discrimination, power, and control (Blommaert \& Bulcaen: 2000). Its other purpose does not provide specific answers, but to expand our personal horizons and to understand our flaws and to make unconnected programs or motivations as well as others. It is real and frequently expanded, and instances of social communication take partially literally. This is a resource for people who are trying to cope with the effects of alienation and deactivation of the changes imposed on them. This theory analyzes spoken or written texts as communication, discussion, dialogue or communication content.

\section{Method}

The discussion is a qualitative method developed by analytics producers (Fulcher: 2010). According to Locke (2004), the prophet cannot represent the world, but by specifying the world, understanding and building the world. McGregor (2010) said that the discourse to express words. Van Dijk (2006) argues that CDA requires an account of true multidisciplinary and complicated relationships between text, discussion, social opinion, energy, society, and culture. Using critical discourse analysis, it is necessary to explain, understand, analyze, and criticize the social life reflected in the text. Speech analysis can be defined as approaching and thinking about the problem. This is meaningful in the world. The definition is caused by the reading or analysis of the meaning of the text.

Locke (2004) argues that the argument is a coherent way of expressing the word's meaning, reflecting human symbolic systems, including speech. They describe the discourse as a concept that is an active relation to reality. The language refers to the fact that the language is in a dysfunctional relationship, referring to objects in the language that is to be presented in reality (Locke: 2004).

Discussions and dialogues bring people the facts about teaching and learning policies to the realm of the situation on the ground. The language is a social and cultural tool, and our reality is socially and culturally constructed (Fulcher: 2010). The language is the heart of critical discourse analysis. Critical discourse analysis can be considered a political intervention with a socially transformational program and suitable for the study of post-racism courses in South Africa.

According to Fulcher (2010), DA can be seen as a way of understanding social interactions. Furthermore, Fulcher (2010) states that a discourse is a matter of text, particularly for identification, for example, a statement that reaffirms a viewpoint or that men see the weddings lag. Research starts with a research question and is not a theory. The conversation or piece of text is copied and then eliminated. The searcher himself tries to identify categories, topics, ideas, views and roles in the text. Identifying the shared resources that are normally shared, that is, to identify spoken sharing patterns.

According to Locke (2004), the discourse also refers to the methods and methods that indicate. Conduct, communicate, evaluate, think, trust, speak, and read and write ways that act as the principles of specific roles of particular groups of particular groups. Locke (2004) further states:

a) The discourse is shaped and restricted by social structure (class, age, ethnicity, and gender) and culture

b) The discourse helps shape and restrict our markings, relationships, and the system of knowledge and beliefs.

c) Systems are shaped and constrained by the language and the justified worlds from us and others.

d) Teaching and learning education policies are made up of social structures, relationships, and differences in different languages spoken in South Africa.

According to Fairclough (1995), "Language theory is an object form and is invested in language theory". Lake (1996) argues that the idea of studying 
the speech in a social context will share critical discourse analysis with sociology and ethno therapy. The discourse is a complex of three elements, such as social practice, discourse practice (text production, distribution, and use), and text, and specific discourse analysis for analysis and their correlation in these dimensions (Fairclough: 1995). CDA of written and spoken texts works in two ways, namely, critical and constructive. The texts are based on major social institutions, such as families, schools, churches, workplaces, mass media or government. Human subjects use texts to create their own meaning and to build social work and relationships in creating different world meanings, concepts and editions, in the same way, to create a place for text and individuals (Lucke:1996). In confrontational events in the classroom, the discourse usually opens in uneven, competitive, and unpredictable social structures.

CDA begins with the acceptance of a subsequent constructor (the scientific objectivism of activists and proponents of universalism) toward the assumption that people have the singular, essential social markings or the stable cultural, social class or gender characteristics. (Lucke: 1996). Discourses are dynamic and cross-fertility, constantly moving and producing in daily texts. Each text is a cultural speech function, social action, forces, audiences, and effects language with a specific shape and feature. All texts are made from recurring statements, such as clams, propositions, and words. Based on their earlier experiences with language and texts, people make sense based on their discourse resources collection.

All texts are indeed multilingual (with different meanings or meanings depending on their use in different discourses), that is, they draw from the scope of knowledge and sound. Critical discourse analysis questions the possibility of a non-cytological statement or text on many sources. All texts are simply standard, shape, and texture rather than simply reflecting and building. The purpose of critical discourse analysis is to make readers and texts with listeners and manipulate them transparently (Lucke: 1996). It can make transparent asymmetries in those relationships; text texts can be disclosed to which texts can be found, detect, define, and in some cases activate and control readers and addresses (Fairclough: 1995).

The construction of official knowledge in schools involves the inverse coverage of text and sites from educated, teachers and corporate publishers to classroom classes and informal discussion, and civil servants prepared legislature and policy letters, prepared by the educational, teachers and corporate publishers. The true speech and writing of students for formal evaluation (McGregor: 2010). The key result is to establish itself as a form of common sense for naturalizing its own functions by appearing in daily texts. The function or function of discourse analysis is to criticize and criticize texts as a way to interrupt the mean sense. Every day we make decisions about daily conversations, the effectiveness, value, and truth of the ads or textbooks.

\subsection{CDA: Interventions}

According to Blommaert and Bulcaen (2000), "Propose a three-dimensional framework to grasp and analyze the discourse:

a) "Discussion is the language-language features of concrete instances and text-like organizationdiscussions.

b) Discussion-like practice, consumed, shared, distributed and distributed in society.

c) The discourse is a feature of debate-socio-practice, that is, theoretical effects and influential processes."

CDA is an intervention of social practices, which critically investigate. This should indicate the amendments to the proposals and specific discourses for change. The meaning of the text does not exist until it is actively used in use. In other words, the discourse can be seen as a situation in use by saying that the process is activated in the text. Textualization is a reconstruction of the reader's intended message reader. The writers' observation product is text. As a descriptive habit, the discourse explores many aspects, including text, contextual, design, and methods. These methods have been developed to examine socially structured methods in classroom rooms and other educational settings.

\section{Result and Discussion}

\section{1 Thematic Analysis}

Theme-specific analysis information is trying to identify meaningful categories or topics in the body (Fulcher: 2010). Howitt and Cramer (2010) suggest that in thematic analysis, the researcher's work identifies a limited number of subjects that accurately reflect their text data. Theme-specific analysis is the method of identifying, analyzing and reporting data (themes) (Braun and Clarke: 2006). A theme is a set of link categories that convey the same meanings and generally emerges through a corresponding analytical process, which is a qualitative model.

By looking at a text, the researcher asks whether the abstraction can be aborted for many repeated things, for example, stability or blasphemy. Data familiarity is important for thematic analysis. After familiarity, researchers can code his / or data. In the Report Results section, abstract topics have been reported and reported. Themes identified in this study were analyzed, and reports and recommendations were made. 


\subsection{Print Text Analysis}

According to Locke (2004), "Texts can be analyzed in the following ways:

Please: Critical Discourse Analysis allows binaries to reveal and compete.

a) Contextualization codes: Reinforces power by a form of repetition.

b) Cohesion: A text together is meaningful, completely sewing. These tools include combinations, pronouns, exhibitors, ellipses, adverbs and repetitive words and phrases. Cooperation helps establish co-operative or subordinate relationships.

c) Discourse Organization: The largest units and paragraphs in which sentences are joined by the organization.

d) Thematic Organization: Postponing symptoms based on the explanatory structure of the editorial."

\section{Conclusion}

In this article, researchers have examined how critical discourse analysis is conducted. Researchers emphasize that critical discourse analysis is primarily localized and can be measured using its language learning standard. Speech can be used to represent beliefs, positions, and ideas about who speaks about a spoken text. Written or verbal messages can mean meaning when analyzing the underlying meaning of the words. Analyzing the underlying meanings can mean the meaning of the problems, rules, and events that educators have. Word usage can help those with control over the education system.

\section{Acknowledgement}

This research was supported/partially supported by Dept. of English Education, FKIP Universitas Lancang Kuning. We thank our colleagues who provided insight and expertise that greatly assisted the research, although they may not agree with all of the interpretations/conclusions of this paper.

\section{References}

Anyon, J. (2009). Theory and Educational Research: toward critical social explanation. London. Sage Publications.

Barnett, T. (2006). Analysing Oral Texts, or How Does an Oral History mean? Los Angeles. University of California.

Blommaert, J., \& Bulcaen, C. (2000). Critical discourse analysis. Annual Review of Anthropology, 29(1), 447-466...
Braun, V. \& Clarke, V. (2006). Qualitative Research in Psychology. Journal of Psychology. Vol.3:77101.

Brenes, C. A. N. (2005). Analyzing an oral narrative using discourse analysis tools: observing how spoken language works. Actualidades Investigativas en Educación, 5(1).

Dressman, M. (2009). Using social theory in educational research: A practical guide. Routledge.

Fairclough, N. (1995). Critical Discourse Analysis: the critical study of language. London and New York. Longman.

Fairclough, N. (2013). Critical discourse analysis: The critical study of language. Routledge.

Flowerdew, J., \& Richardson, J. E. (Eds). (2017). The Routlegde handbook of critical discourse studies. Taylor \& Francis.

Fulcher, R. (2010). Critical Discourse Analysis. London and New York. Longman.

Hamuddin, B. (2012). A comparative study of politeness strategies in economic journals (Doctoral dissertation, University of Malaya).

Hamuddin, B. (2015). DISCOURSE ON MEDIA: Bringing Hot News into ELT'S Classroom Discussion. Proceedings of ISELT FBS Universitas Negeri Padang, 3, 87-95.

Han, C. (2015). How to do critical discourse analysis: A multimodal introduction.

Howitt, D. \& Cramer, D. (2010). Introduction to Research Methods in Psychology. 2nd edition. Harlow. Pearson Education Limited.

Locke, T. (2004). Critical Discourse Analysis. London: Cromwell Press

Lucke, A. (1996). Text and Discourse Analysis. New York: American Educational Research Association. Vol. 21:3-17.

Maxwell, J. A. (2010). Essay Review of Jean Anyon's Theory and Educational Research: Toward Critical Social Explanation. Education Review//Reseñas Educativas.

McGregor, S.L.T. (2010). Critical Discourse Analysis: A Primer. Halifax. Mount Saint Vincent University

Morgan, A. (2010). Discourse analysis: An overview for the neophyte researcher. Journal of Health and Social Care Improvement, 1(May), 1-7.

Okot, M.B. (2007). Text and Textuality in Oral Performance. London. Sage Publications. 
Olson, B. (2007). Quantitative "versus" Qualitative Research: The Wrong Question. Edmonton. University of Alberta Press.

Rogers, R. (2017). Reclaiming powerful literacies: New horizons for critical discourse analysis. Routledge.

Rogers, R., Malancharuvil-Berkes, E., Mosley, M., Hui, D., \& Joseph, G. O. G. (2005). Critical discourse analysis in education: A review of the literature. Review of educational research, 75(3), 365-416.

Sari, R., Putri, S. E., Herdi, H., \& Hamuddin, B. (2018). Bridging critical discourse analysis in media discourse studies. Indonesian EFL Journal, 4(2), 80-89.

Simangunsong, W. P. S. M., \& Ali, D. S. (2018). Critical Discourse Analysis: As an Empirical and Rational Foundation.

Suppes, P. (1974). The place of theory in educational research. Educational researcher, 3(6), 3-10.

Van Dijk, T.A. (2006). Principles of Critical Discourse Analysis. Amsterdam. University of Amsterdam.

Wodak, R. (2009). Aspects of Critical Discourse Analysis. London. Sage Publications.

Wodak, R., \& Meyer, M. (Eds.). (2015). Methods of critical discourse studies. Sage. 